\title{
Breaking Out of Academic Isolation: The Media Odyssey of a Sociologist
}

\author{
Steven M. Ortiz
}

Published online: 26 October 2007

(C) Springer Science + Business Media, LLC 2007

\begin{abstract}
The professional development of sociologists involves specialized training through which we acquire and apply numerous skills. However, it is unlikely that our professional socialization includes training in how to inform the public about sociological knowledge and research through media involvement. As a sociologist who did not receive such training and was not prepared for the enormous unanticipated media and public interest given to my research topic, I provide a personal account of my unexpected metamorphosis into a media self and my experiences working with the media. I describe the nature of my professional and media obscurity, provide an overview of my initiation into media culture, and explore a self-transformation process that became necessary to manage the responsibilities associated with the media-assigned role of expert. I identify and examine the lessons I learned through extensive media involvement and the emergent realities of this involvement. Based on my experiences and resulting awareness of media culture, I offer to the discipline some suggestions and guidelines for media involvement and advocate for media training.
\end{abstract}

Keywords Media experiences $\cdot$ Media relations $\cdot$ Professional sociology

The professional development of sociologists involves several stages of training and experience. It usually begins with graduate training and gradually includes more specialized training within which the sociologist acquires and develops occupational

Earlier versions of this article were presented at the annual meetings of the Pacific Sociological Association, 2004, 2006, and the Society for the Study of Symbolic Interaction, 2002. I wish to thank Mark Edwards, Mark Floyd, Jacque Lynn Foltyn, William Loges, William Lunch, Larry Pribyl, Todd Simmons, and Rebecca Warner for their insightful comments and supportive suggestions.

S. M. Ortiz $(\bowtie)$

Department of Sociology, Oregon State University, 307 Fairbanks Hall, Corvallis,

OR 97331-3703, USA

e-mail: sortiz@oregonstate.edu 
expertise. Largely absent from our professional preparation is training in working with the media. The emerging interest in topics such as public sociology, which has lately been the center of a lively discourse (Burawoy 2005a; Gans 2002; McLaughlin et al. 2005; Turner 2005), may reflect this gap in professional socialization. Whatever position is taken in this continuing debate, it is generally agreed that communication with the public continues to be a challenge for the discipline. When media involvement includes "live" television and radio, communication can be particularly risky and extremely stressful. This presents the profession with three fundamental questions, which I have confronted in my own career. First, to what extent do we have a responsibility to the public to share sociological knowledge and research, or address social issues (e.g., Brady 2004)? Second, how can we effectively work with the media without shortchanging other professional responsibilities? Third, how can we effectively work with the media without compromising our scholarly integrity?

Some sociologists have discussed their intentional and unintentional involvement with the media and addressed the professional significance of media involvement (e.g., Adler 1984; Best 1986; Stacey 2004: 140-42; Vaughan 2004). Others prefer to maintain academic isolation, remaining within the walls of the ivory tower (e.g., Etzioni 2005: 375-76; Nielsen 2004). With few exceptions (e.g., Adler 1984; Best 1986, 2004; Stacey 2004; Vaughan 2004, 2005), sociologists seem reluctant to identify, examine, or document their media experiences. Given the significance of sociological knowledge and research and how it benefits society, and the power of the media as a tool to disseminate information (Altheide 1985), I have come to believe it is a mistake to avoid this aspect of our professional service. Furthermore, I believe that formalizing media training could better equip sociologists to engage the public during their careers, and help to strengthen the profession-without deferring to the needs and interests of the media. Moreover, media training can address the concern sociologists have about the public invisibility of sociology and help to establish its disciplinary identity (Boyns and Fletcher 2005).

Similar to the experience of other sociologists, my involvement with the media was quite unexpected. As a scholar specializing in the study of sport marriages, I was abruptly cast into the role of "expert" (i.e., an expert "source" in my area of specialization) (Altheide 1984: 188; Ortiz 2002a). Like Best (1986: 373) and Vaughan (2004), I was extremely surprised at the swiftness and intensity of media attention to my research. I was a newly minted assistant professor when I was suddenly thrust into the spotlight. I did not at that time have an article in a popular magazine or a book with which to establish my credentials and expertise (Best 1986, 2004; Vaughan 2004, 2005); I had simply presented a paper at an annual meeting of the American Sociological Association (ASA) that examined how the possibility of sexual infidelity can be a source of stress for wives of professional athletes (Ortiz 2001a). Since this initial involvement with the media, and subsequent involvement when the fast-breaking news story about National Basketball Association (NBA) superstar Kobe Bryant generated substantial national interest, I have tried to make some sense out of my experiences. I was not trained or in any way prepared for these experiences, and I regard them as a media socialization process or a type of informal professional training ("on-the-job training") —one that resulted in my unexpected metamorphosis into a media self. In retrospect, I believe my professional 鱼 Springer 
socialization has included and benefited from a serendipitous media socialization process. This socialization process includes providing accurate information to the media about my research on sport marriages - specifically about wives of professional athletes, offering my views on the world of sports, discussing my ethnographic methods (e.g., Ortiz 2001b, 2004, 2005), and dispelling misconceptions and misinformation about the wives, my research findings, and sociological research in general.

The socialization process I experienced involved a self-transformation process that was catalyzed by the media. This self-transformation process began when I was assigned the role of expert on sport marriages, and evolved as I learned to manage this role while trying to avoid what Adler (1984: 320) has described as "getting puffed-up" or experiencing "feelings of self-importance." Abandoning the familiar comfort of my scholar self, I learned to alternate between my scholar self and my media self. I learned to accurately, effectively, and responsibly provide information to the media and also perform my other professional responsibilities.

Moreover, this socialization process involved a deepening awareness of how important it is to me to maintain professional integrity. Because I feel a keen sense of responsibility to the profession, I became very conscious of how I presented myself, and how I represented my department, my university, and the discipline to the media and thus to the public (Goffman 1959). Although I had this awareness in the classroom, at conferences, and in other professional situations, being conscious of my self-presentation became particularly significant and stressful when working with the media. I wanted to avoid saying anything that once it became public record - could be misunderstood, viewed as controversial, or embarrass, discredit, or stigmatize me (Goffman 1963, 1967a). I realized that these representations may be at odds with the media's interest in presenting a dynamic interview with an engaging person about a provocative topic. In addition, I became aware that my unique knowledge of the topic and my credibility as an expert source made it possible for me to establish some conditions on my involvement - although I realized it was necessary to limit the conditions in order to retain my value to the media and take advantage of the opportunity to inform large audiences about my research.

Based on my firsthand, personal experiences, this article provides insight into professional participation with the media. It offers some observations about media involvement and expands on issues, processes, and concepts identified by sociologists who have had similar experiences. First, I describe the nature of my professional and media obscurity and origins of my scholar self and media self. Second, I provide an overview of my initiation into media culture (Altheide and Snow 1991) and my experiences in what, for me, was an uncharted landscape. Third, I explore a self-transformation process that became necessary to manage the responsibilities associated with the media-assigned role of expert. Fourth, I identify and examine the lessons I learned through confronting several emergent realities that I became aware of as my engagement with the media deepened. Fifth, I offer to the discipline some suggestions and guidelines for media involvement and advocate for media training. In concluding, I discuss some initial steps I have taken to support sociologists who share my concerns and acknowledge the need for media training as part of our professional development. 


\section{Professional Obscurity: Origins of a Scholar Self}

A sociologist's professional socialization involves expectations, presents challenges, and includes certain fears (e.g., fear of failure) that become evident early in our graduate training (Adler and Adler 2005; Ferrales and Fine 2005; Shulman and Silver 2003). For instance, choosing a dissertation topic is one of the most important choices we make. I once heard a professor say that graduate school has less to do with intellect and more to do with motivation. Taking this to heart, I knew the motivation to complete my dissertation was crucial. During this period of discernment, graduate students may be advised that certain dissertation topics are not always supported by the profession, and it may be suggested that we select a socially relevant topic, particularly if we want to increase our opportunities in the academic job market and successfully launch our career trajectory. At any point in our career, we may have difficulty deciding whether we want to be involved with the media for the same reasons. Like other graduate students, I explored different dissertation topics in my quest for the right one. I wanted to select a topic that would serve two purposes: make a genuine contribution to the discipline and to public knowledge, and establish an area of professional expertise. As a graduate student in the sociology department at UC Berkeley, I was influenced and inspired by its culture of entrepreneurial sociology, which encourages graduate students to design and develop research projects that are not related to faculty research (Burawoy 2005b: 44; Duster 1987: 83-84). ${ }^{1}$ After considerable reflection, I decided to focus my research on the wives of professional athletes, using an ethnographic approach to data collection. Although my mentor and a few other faculty members and colleagues supported my decision, several others inside and outside the department strongly suggested that I select a more substantive and significant research topic (e.g., Nichols 2005: 4). Many reasons for this well-intentioned advice were given (e.g., potential difficulties in gaining access to the wives, probable waste of valuable time and resources, lack of sociological relevance, and the potential for a career setback).

The tentative institutional support and interest in my topic is one of several challenges I confronted early in my career. It has been a journey filled with difficult choices and decisions. As a "freeway flyer" for many years, my status as faculty was clearly marginal at best. I labored in what seemed to me like the salt mines of professional obscurity. In some ways I was, as Goffman (1959: 151-53) might put it, an academic "non-person." As an itinerant lecturer, I commuted from one university to another, teaching on a part-time and temporary basis at three or four different universities year-round (e.g., Nichols 2005: 4). At one point, I simultaneously taught five different courses at three universities during the same term. I flew from one university to another interviewing for positions, hoping to be offered a tenure-track position, without success. During this period of career instability, I often wondered whether my research topic was hindering my opportunity to obtain a full-time position.

\footnotetext{
${ }^{1}$ Burawoy (2005b: 44) has identified this approach as the "independent scholar" model.

Springer
} 
In retrospect, this tenuous support for my research topic left me unprepared for the intense interest that came later in the form of media and public attention. In my opinion, a major reason for the media's fascination with my research topic is the widespread popularity of sports (e.g., Raney and Bryant 2006). Adding celebrity and sexual misconduct or other discreditable behavior to the mix heightens its appeal. However, I believe the relevance of this topic goes deeper than any sensationalized image of professional athletes and their wives, and my work with the media provides an opportunity to increase disciplinary and public awareness of these issues. The sport marriage is a misunderstood institution, and the wives' private pain that results from attempting to cope with the many demands, pressures, and stressors in their "career-dominated" marriages to professional athletes has remained largely invisible or is taken for granted within the discipline. ${ }^{2}$ Although it was never my intent, the tremendous outpouring of media and public interest has confirmed my belief in the sociological significance of the sport marriage and the opportunity it provides to examine these women's marital experiences. Not only has the media responded with fervor, but I continuously receive a steady stream of e-mail from athletes' wives and interested others. The research I have conducted with these wives provides insight into the experiences of husbands and wives in other career-dominated marriages and in other families in general.

\section{Media Obscurity: Origins of a Media Self}

Two of my professors at UC Berkeley were widely recognized as experts in their field. They became the focus of considerable media attention during my graduate training, and their professional activities have continued to draw attention throughout their careers. As their teaching and graduate assistant, I was fortunate to closely observe how they interacted with the media. I was deeply impressed with and influenced by their professionalism - not in the least suspecting that I would be the recipient of similar media attention early in my career. I am grateful that the memories stayed with me, because I have been able to draw on them in my own experiences with the media.

Representatives of the media first approached me while I was completing my dissertation on sport marriages (Ortiz 1994). To this day, I am uncertain how they learned about my research. During National Football League (NFL) Hall of Famer and actor OJ Simpson's widely publicized criminal trial, a journalist expressed an interest in interviewing me for a magazine article focusing on violence against women in sport marriages. Shortly thereafter, I was contacted by producers for an HBO sports program and ESPN who were developing projects focusing on the same social issue. Because I had spent considerable time doing the fieldwork and therefore was hard pressed to finish writing my dissertation - which needed to be my priority - I declined their requests. I reasoned that if I gave interviews, the significance of my research findings might be overlooked, distorted, or sensationalized in media coverage of the trial, or my views might attract more media interest than I was comfortable with or had time for. In

\footnotetext{
${ }^{2}$ For an analysis of sport marriages and how women experience their marriages to professional athletes, see Ortiz $(1997,2002 b, 2006)$.
} 
other words, I decided it would be professionally wiser and safer to avoid the media. I was inexperienced not only in reporting the research findings and identifying their relevance with confidence, but also in interacting with the media. At this early stage in my career, I was reluctant to take this professional risk. After I graduated, logged countless miles driving from one university to another as a nomadic lecturer, gained experience as an instructor, and contended with a competitive job market, I was again cautioned by well-intentioned colleagues to avoid the media. I was told that sociology departments do not seek or hire what have been referred to as academic celebrities or self-indulgent celebrities (Brady 2004: 1637). Because I was having difficulty finding a tenure-track position and did not wish to jeopardize my future career, I accepted this as sage advice.

Looking back with greater awareness about the relative nature of obscurity, I realize that my media obscurity came to end when my professional obscurity ended. After arriving at Oregon State University (OSU) in fall 2000 and becoming an assistant professor, I continued to believe that avoiding the media was a prudent strategy. With the encouragement of colleagues and the media staff at the university, I gradually changed my mind. I realized that I had a responsibility to share my research findings with the public, and that this should be my professional concern. This realization outweighed my preference for media obscurity and prompted me to emerge from my self-imposed academic cocoon. Therefore, in the beginning of the second year of my appointment when my conference paper received a deluge of media interest, even though I had no media experience or training, I responded to the cascading requests for interviews - far exceeding departmental expectations for junior faculty members. Surprisingly, interest persisted, and my decision was tested 2 years later when Bryant was charged with sexual assault and confessed to adultery. I was again cast into the role of expert, becoming inundated with interview requests over a much longer time period and with even greater intensity than during my initial experience.

\section{In the Spotlight: Origins of an Expert Source}

During winter term 2001, influenced by my new position, concerned about the performance of my professional role, and aware of my desire to be accessible and provide sociological knowledge to the public, I consented to an interview for the Kansas City Star for an article about dating preferences among student athletes at a Midwestern university. However, my sustained involvement with the media actually began a few months later after the university's director of news and communication services asked for my permission to prepare a press release on some aspect of my research (Best 1986: 374-75). He was interested in my research on sport marriages, and wanted to acquaint the local media and the community with me as a new faculty member on campus and a family/sport sociologist. Eventually, and reluctantly, I concurred. During spring term, I informed the director that I was presenting at ASA's annual meeting a paper that examined how the possibility of sexual infidelity can be source of stress for wives of professional athletes, and that this could be the basis of a press release. He agreed. During the summer, he interviewed me about the findings reported in the conference paper. Keeping in mind that the language of the 黑 Springer 
profession is not always the language of the public, during that interview I attempted to convey the concepts and findings in ways I believed the public could easily understand. After he drafted the press release, I proofread it and consented to its release. He wanted the information to be available when media interest would be at its greatest - the day of the paper presentation - so he released it the Friday before the conference began. I delivered the paper the following Monday morning.

After the session was over, as I was preparing to leave the room, I was approached by a public information assistant from the ASA media center in the main hotel. I could sense her excitement as she gave me a big smile, introduced herself, and told me there was some media interest in my paper. Specifically, there were requests for telephone interviews from the Globe and Mail in Toronto and a British Broadcasting Company (BBC) radio station in London. Later, as I was walking to the media center to do the interviews, I checked my voice mail and discovered it was filled to capacity with requests for interviews from regional and international media. Although the news director had told me the press release would have great national appeal, and I had therefore anticipated some interest, I was dumbfounded at the magnitude of the media's response. I thought, "It's only a conference paper. There must be a mistake." From that moment on, my media socialization was well underway.

Over a sometimes exhilarating yet stressful and exhausting two-day period in the media center, I was deluged with requests for interviews. As Adler (1984: 313) so aptly put it, "I was 'media blitzed." During the remainder of the conference, I participated in at least 11 telephone interviews (i.e., three prerecorded/live radio interviews and three newspaper interviews on Monday, and five prerecorded/live radio interviews on Tuesday). This number does not reflect the total number of requests for interviews - those I declined, those I could not do given the reporter's or producer's timeframe, and those I was unable to do because my schedule did not allow me to participate. Although some of the interviews were conducted with regional media outlets in Oregon (i.e., three prerecorded/live radio interviews and one newspaper interview), the majority were conducted with international media outlets in Australia, Canada, and England (i.e., five prerecorded/live radio interviews and two newspaper interviews). In addition, I later learned that the producer of a popular national television morning talk show had tried in vain to contact me for an appearance.

\section{Riding the Waves of Media and Public Attention}

What occurred following the paper presentation vividly illustrates what Adler (1984: 315) experienced and what Altheide (1984: 179-80) has referred to as the ripple effect. To me, the ripples felt more like waves. Keeping this idea in mind, I identified three progressive and momentum-gaining phases of media and public interest. The press release prompted the initial wave of media interest. This was sustained, and an interview I did for a newspaper article prompted a second wave. A third wave consisted of public interest. These waves of interest do not always occur in the ways I experienced them. Media interest can be triggered at any time (e.g., over a period of a few days or many months or years) during either an absence or an intensity of media interest. Many possible trigger points can generate new, continued, or 
sustained interest. Like opening Pandora's box, once the article, story, commentary, or press release is available - especially on the Internet-it is permanent and selfperpetuating. Altheide (1984: 187) has described this pervasive pattern of media involvement as media incest.

As the initial part of the first wave, the press release was sent to different wire and electronic services (e.g., Associated Press). Subsequent news stories and features appeared in print outlets (i.e., syndicated newspapers) and were carried by wire service outlets, and over the Internet on a wide range of websites. These sources were accessed by journalists, newspaper reporters, and producers of news- and sports-talk radio programs (e.g., BBC World Service Radio) and television newscasts. After returning home from the conference well over a week later, I assumed that my conference presentation had become old news, so I was quite surprised to find numerous acknowledgments via voice mail and e-mail from family members, friends, well-wishers, and even strangers in addition to more requests for interviews. Media interest persisted during the fall and was characterized by several trigger points that sustained this wave of interest. I was interviewed on regional and international news- and sports-talk radio programs (e.g., Detroit, Minneapolis, Seattle, and Perth), for national newspapers (e.g., New York Times), for local and national print magazines (e.g., Sports Illustrated), and for an informational website (HealthScoutNews). German media outlets also requested telephone interviews. The ASA acknowledged this extensive media coverage in an issue of Footnotes (Levine 2001).

As a subsequent part of the first wave of media attention, I continued giving interviews on international news- and sports-talk radio programs. Regional and international newspapers continued to pick up and carry or comment on the press release and related stories. Permutations were evident. Initially, the media were clearly interested in the sport marriage (and thus the wives of professional athletes) because of the husbands' celebrity status as professional athletes, and because little is known about the sport marriage. The media had defined me as an accessible scholar who is a credible source of information on the topic. As one reporter said during our interview, "Who else can we go to? You're the expert. You're the only one we know of who has done this kind of research." Media attention reached a plateau when I was contacted for interviews about my research for newscast segments, and for stories about the sport marriage or sports-related social issues (e.g., the Gold Club scandal involving exotic dancers and well-known professional athletes, the tenth anniversary of NBA superstar Earvin "Magic" Johnson's announcement that he is HIV-positive) on international news- and sports-talk radio programs, local television stations, national television sport programs (e.g., HBO's Real Sports, ESPN's Pardon the Interruption), and international television sport programs (e.g., TSN's Off the Record, Canada).

A second wave of less intensity broke in the winter of 2002, when I was interviewed for a newspaper article about the possible divorce of former NBA icon Michael Jordan and his wife Juanita, and about the precarious nature of sport marriages in general. After the article appeared, I naively assumed interest would diminish. Nevertheless, with Jordan's name now in the headlines, a surge of 
attention followed and the story was picked up and featured in local, regional, and international newspapers. During the next several months, I was interviewed on international news- and sports-talk radio programs (e.g., Melbourne, Toronto) and for regional and international newspapers (e.g., Chicago Sun-Times, Atlanta JournalConstitution, Indianapolis Star, Weekend Australian, and [Scotland] Sunday Mail) about sport marriages (e.g., race-car drivers' marriages as part of the media coverage of the Indianapolis 500), the groupie phenomenon, and other sport topics (e.g., an Australian rugby team controversy). Thus, beginning with my initial media experience, over a 20-month period I participated in roughly 34 interviews (i.e., 18 prerecorded/live radio interviews, 13 newspaper interviews, two print magazine interviews, and one website interview). Additionally, there was a proliferation and consistent flow of Internet activity, with various websites posting the press release, feature stories, articles, and commentaries-locally, regionally, nationally, and internationally.

The third wave emerged in the form of an outpouring of public interest. As a result of the massive publicity, the public soon became aware of my conference paper and revealed a keen interest in my research. Surprisingly, for example, after doing the interview for Sports Illustrated, the brief article led to numerous requests for further information by the magazine's readership. This unexpected wave of interest continued the information-dispensing process initiated by the media culture. Similar to Best's (1986: 380) experience, friends and acquaintances sent clippings from a variety of newspapers around the country, thus alerting me to the extent of newspaper coverage. For several months, I was inundated with requests for my publications, conference papers, and anything that might provide additional information about my research findings. These requests came from colleagues, graduate students, family therapists, and wives of professional athletes (i.e., many sought support for marital crises, shared personal testimonies about marital issues, provided support for my research, agreed with or attempted to confirm my findings, and reassured me that I was "on the right track"). As part of my effort to engage the public, I also accepted invitations to discuss my conference paper, my research, and my media experience with different groups on campus, in the community, and in the state.

\section{“Are You Available?”: A New Wave Begins}

I was busy grading final examinations for my introductory sociology course in July 2003 when the live-breaking news story about Bryant's sexual assault charge caught my attention. I was curious and decided to watch the press conference he held on a Thursday. With his wife Vanessa sitting beside him, Bryant confessed his infidelity and mentioned the word "adultery." Suddenly, my availability to the media became a professional and personal dilemma. I was torn between my obligation to respond to the media interest I knew would follow (and thus inform the public), and my desire to avoid excess stress and maintain academic stability. I decided that informing the public and fulfilling my obligation to my university and to the profession by disseminating sociological knowledge should come first. Because of Internet search engines, from that moment on I was again thrust into a media frenzy. 
Television/radio producers and reporters quickly connected Bryant's confession of adultery to my phrase "culture of adultery" (as identified in the press release for the conference paper), and I was again flooded with requests for interviews by media outlets of all types. For instance, $A B C$ World News Tonight tried to contact me on the day of the press conference to schedule a prerecorded television interview for Friday that would broadcast on Saturday. Although I wanted to respond to media interest, I decided not to respond to this initial request, or to additional requests for interviews, until I finished grading examinations and submitting final grades. After submitting the grades and began teaching my next summer course that week, I appeared on Dateline $N B C$. That appearance, together with radio and newspaper interviews I gave during a very hectic week (presumably as more of the media discovered the press release and as I received more exposure), created another wave of interest. I was blitzed again as the surge of media attention gathered momentum. Over the next few months, I selectively accepted requests for appearances on national television (i.e., Anderson Cooper 360 , Big Story with John Gibson, and MSNBC Live), interviews with regional newspapers (e.g., Chicago Sun-Times, [New York] Daily News, Denver Post, Miami Herald, Oregonian, [Riverside] Press-Enterprise, and [Newark] Star-Ledger), and on regional, national, and international news- and sports-talk radio programs (e.g., Los Angeles, New York, San Diego, San Francisco, Toronto, Francisco, and Toronto). Also, my research was featured on national television (e.g., Countdown with Keith Olbermann) and in other media outlets. During a four-month period I participated in at least 28 interviews (i.e., four prerecorded/live television interviews, 13 prerecorded/live radio interviews, eight newspaper interviews, one online magazine interview, and two prerecorded television interviews that were never broadcast).

Although I became aware of a spin-off effect during my initial experience, the pattern was increasingly evident after the Dateline $N B C$ appearance. As with the earlier Jordan newspaper story, one particular newspaper article for which I gave an interview was picked up and syndicated in many local and regional newspapers. Based on one of these articles in a regional newspaper, a sports-talk radio producer in the same city contacted me for an interview. The patterns of coverage reflected a stronger national interest than was apparent during my initial experience. A similar pattern was evident when I was contacted by People Magazine after a person associated with the magazine had listened to me speak on a sports-talk radio program. A surge of public interest followed this extensive media attention but, compared to my initial experience, this wave of public interest was greater. Following my paper presentation, attention primarily came from regional and international media with an interest in the issue of marital infidelity among male professional athletes. Later, the national media became interested only when my research was believed to be applicable to a hot story involving a male sport celebrity.

\section{Understanding the Media Culture}

Over the years, I have encountered members of the media who were patient, understanding, inquisitive, and ethical. In retrospect, I would say that distortions or inaccuracies about my research and my comments have been surprisingly minimal. On the other hand, I learned there are no guarantees and that believing I have any 
control over what media representatives do with my words and my public image is naive. For example, a few of the conceptual terms used in the conference paper and press release were instantly translated into what I regard as "mediaese." Although the use of descriptive language illustrates a sociological and media compatibility that can result in more effective communication with the public, I discovered that such mediaese can be the basis of and is sometimes limited to misleading or overly simplified "sound bites" in an attempt to titillate or appeal to viewer interest. Consequently, a 30-minute prerecorded television interview can be reduced to a 10to 15 -second sound bite during the broadcast. Sound bites can be taken out of context, or all context can be lost. Other sources of frustration and exploitation include the practice of television producers turning their research into an interview. For instance, I was interviewed extensively by two producers who explained that certain information was required before doing the prerecorded interview for a national television news program. Their intent was to qualify me as an expert source, thus giving credibility to the segment. At the conclusion of the second interview, I was informed that I would be contacted at a later date to do the prerecorded interview, but I was never contacted and the segment was broadcast a few days later without giving recognition or acknowledgment to me for my contributions. I have since been told by a television executive that these practices are typical. As mentioned, doing a prerecorded or live television or radio interview is stressful and can involve considerable time and effort (e.g., reviewing notes and rearranging work schedules, meetings, and other duties and responsibilities). It can be irritating to be informed that for various reasons producers decided to cancel a live interview or not to broadcast a prerecorded interview. This occurred fairly frequently in my work with the media. ${ }^{3}$

Another way the media took my participation for granted was evident when I appeared on a national television news program. During live coverage of the Bryant trial, I agreed to be available for comment from the television studio at my university. After patiently waiting through most of the broadcast for them to ask me questions, they finally cut to me for a few comments and then the program was over. However, neither I nor the television production crew was informed we were off the air. Trying to be a cooperative guest, and on the instruction of the crew, I continued to wait expectantly for 15 to 20 minutes before we were told we were no longer live. I felt discarded. This lack of control over how I was treated and over the outcome of interviews into which I had invested so much time and energy was frustrating. My lack of control was also evident when I realized that I could only hope to be accurately quoted in the print media. Moreover, I was frequently contacted (e.g., telephone, voice mail, and e-mail) to do an interview, agreed to do it, scheduled itsometimes changing my existing schedule to accommodate the interview-and then was never contacted again.

\footnotetext{
${ }^{3}$ For example, I did an off-camera qualifying interview for a national television news program, but the producer decided to drop the segment; I did prerecorded interviews for a regional television news program and a national television sports program, but they were not broadcast; and I did an extensive interview for a national sports magazine article on the groupie phenomenon, but it was never published.
} 


\section{Doing Media Work: A Self-Transformation Process}

Although I was cast into the role of expert as the result of a transformation process catalyzed by the media (and did not present myself as an expert on sport marriages), and although I had no media training or experience upon which I could draw, I found that the self-transformation process of shifting back and forth from my scholar self to my media self involved media work. I use the term media work here to identify the self-management and interactional strategies interviewees such as scholars use and the socialization processes they experience when actively participating with media representatives. My media work involved establishing and managing media relations, constructing a "media face," using impression and emotion management strategies, and managing media desocialization.

\section{Establishing and Managing Media Relations}

My initial media experience was extremely stressful. Over time, because I felt a responsibility to the public, and because I was representing my department, university, and the profession, I became painfully aware that the quality of my comments when interviewing, my self-presentation in television appearances, and the quality of media relations were important and had to be professionally constructed. In fact, I discovered that even after I had some experience working with the media, the level of stress remained high. As I gained experience, I relied on a number of strategies. I found that establishing cordial relations and good rapport with media members may help to minimize stress and anxiety. For example, when asked by producers, journalists, and reporters if I was available for a comment or an interview, I was careful not to respond too quickly; I would not commit myself unless I was certain I could fulfill the obligation. I tried not to alienate anyone even when declining requests for interviews. On one occasion, after I declined one producer's persistent requests to appear on a national television news program, I referred the producer to a noted authority who subsequently appeared on the program, and the producer was quite appreciative.

\section{Managing My Scholar Self and Constructing a Media Face}

As discussed, learning how to interact effectively and preserve professional relations with media representatives included learning how to manage expectations and perceptions of me as an expert with knowledge about the sport marriage without feeling self-important or defining myself as a celebrity (Adler 1984: 320-24). Not taking flattery and comments about my expertise seriously was an ongoing challenge as I shifted back and forth from my scholar self to my media self in my interactions with media members, colleagues, and others. My performance of the expert role frequently involved my media self, and my media self was often expressed in this role. To avoid feelings of self-importance and becoming an "expert self" at the expense of my media self, I attempted to maintain some distance between my media self and the expert role (Goffman 1961). Although I took my involvement seriously, I think I succeeded in not taking myself too seriously. I often used humor or selfdeprecation as strategies to minimize feelings of self-importance (both privately and 
with others). Like Adler (1984) and Best (1986), I reminded myself that celebrity was fleeting and at best temporary, and that sooner or later things would get back to normal.

Was there a cost to my scholar self during or as a result of my involvement with the media? During these experiences, I realized that some kind of self-transformation was necessary to effectively respond to media and public attention, and to effectively shift from my scholar self to my media self. The key to this transitional process was to avoid losing my scholar self by completely becoming a media self, or worse, an expert self. It was essential not to allow my scholar self to be swept away in the waves of media and public interest in my research. Therefore, it was necessary to construct and present the appropriate "face" (Goffman 1967b) in interactions with the media. Although my media face included aspects of my scholar self, I made an effort to keep my scholar self separate from my media self and from media and public attention. My media face was a necessary aspect of my media self and I relied on it during radio and television interviews, but I had to keep in mind that it had more to do with my situated and media-induced identity, and less to do with my scholar identity and sense of self (Adler 1984: 321).

\section{Using Impression and Emotion Management Strategies}

My experiences with the media were stressful for other reasons. Although I was inexperienced, I realized that one of my goals in getting involved with the media was to be as precise and consistent as possible in providing information during the interviews and to do whatever I could to ensure that I was accurately quoted. Moreover, I was quite conscious of my media face, and that my "face-work" (Goffman 1967b) was very important because, again, I was representing my department, my university, and the profession. Early in my impromptu media training I learned to, through my face work, present a sincere and confident media self and thus a credible media face. However, presenting such a media face is challenging. I did not want to embarrass myself or to say anything unintentionally offensive or inappropriately humorous during a live interview (e.g., slip of the tongue, faux pas), especially on national television. I wanted to deliver my comments accurately, articulately, effortlessly, and confidently, but I did not always feel competent, centered, articulate, or confident. I wanted to convey interest in being interviewed and my enthusiasm about my research topic, but I did not want to seem overly eager or overbearing. As Best (1986: 379) discovered, if the goal is favorable coverage, these strategies seemed important to me. I reasoned that how sociologists present themselves to the media, and thus to the public, may be just as important as how they present their research findings, despite the fact that the content of the research findings or sociological knowledge surpasses both in significance. As representatives of our profession, self-presentations can be an important aspect of media involvement because we are creating and contributing to the "public face" (e.g., Boyns and Fletcher 2005: 5-7) or the "public image" (Lee 1976: 934) of sociology (e.g., the profession, discipline, research, knowledge, and opinions). Realistically, the messenger may be as important as the message. An important goal of media involvement is to make research findings informative, interesting, and understandable to the public, and the presentation of a scholar self in 
the delivery of research findings or sociological knowledge can be a significant part of this process. In my attempts to fulfill these professional objectives, I relied on impression and emotion management strategies (Goffman 1959; Hochschild 1990). ${ }^{4}$ I came to regard these interactional strategies as media strategies, which I learned and also relied on as part of my media socialization.

During my first media experience, I soon learned that because of my research experiences I was much more accustomed to the role of interviewer than the role of interviewee. Initially, I discovered that reversing these roles could be difficult and awkward, and this contributed to the stress I experienced during newspaper and radio program interviews. Thus, as a way of managing my anxiety as I sat in the proverbial "hot seat" as an interviewee (which always seemed to get hotter during the interviews), I constructed and applied certain impression and emotion management strategies that proved quite useful. These strategies became increasingly necessary as I became more conscious of the professional image I was presenting, particularly later when appearing live on television and radio programs. For instance, to cope with stress during these performances (Goffman 1959), I tried to manage the impression that I was cool, calm, collected, and credible. Even the waiting period during the commercials can be stressful, so I relied on "backstage" (Goffman 1959: 112-40) strategies such as taking deep breaths to try to relax myself, reminding myself of the key points I wanted to identify or emphasize, collecting my thoughts, or quickly looking over my notes for focus and confidence. This "solitary labor" would often include a variation of internal and private "self-talk" (Goffman 1981a: 81) as I rehearsed my lines or concentrated on the key points. As a way of remaining calm as I listened to the commercials or programs and waited for the producer's voice over the telephone or earpiece to inform me that I was on the air, I relied on "emotion work" and followed what I assumed were the "feeling rules" (Hochschild 1979) inherent in the on-the-air interaction in these media formats (Altheide 1984: 181-85; Altheide and Snow 1991). In my effort to be "up," alert, and personable when I presented my media self, particularly when I was tired, I would suppress my nervousness before I spoke with the producer after making contact with the radio station; during my discussion with the producer to learn, clarify, or confirm specific information and assorted details; as I waited for the commercials to end; as I went on the air; and as I responded to questions during the interview. Because of the hasty or instantaneous nature of these media formats, even with practice or repetition, the use of impression and emotion management strategies may not always be effective and can be difficult when giving a performance.

I found that certain "surface acting" and "deep acting" (Hochschild 1990: 12022) strategies were more effective than others in my effort to present a suitable media face when discussing my research and responding to questions during the interviews. In my attempt to routinize the questions as a way of minimizing my nervousness during an interview, I found it particularly effective to use the deep

\footnotetext{
${ }^{4}$ Some form of emotion management (e.g., emotional labor) is usually necessary in various occupations (e.g., Hochschild 1983; Leidner 1999; Mac Rae 1998; Martin 1999), including our own occupation (e.g., teaching, research, service, and administration) (Bellas 1999). 
acting strategy of visualizing the newspaper reporters, radio program hosts, and television program producers as students in a classroom listening to my lecture, raising their hands and asking questions. Later, when doing prerecorded or live television interviews, I took into account certain "expression rules" (Hochschild 1990: 122-24) that were consistent with managing my composure and demeanor (Goffman 1967c) (e.g., not expressing arrogance or passivity) in my use of surface acting strategies as part of my face work in my effort to convey confidence, credibility, and affability.

I tried to present the "right" media face to media representatives and audiences and to put some energy into the performance. I was very careful to avoid presentations of a media self that could be viewed as stuffy, boring, moody, or arrogant, but this proved challenging because many of the same questions were asked repeatedly. I had to deliver my comments in exactly the same way without appearing distracted, rude, or abrupt. As part of my face work, I had to make it appear as though I was responding to the questions for the first time. I was able to do this because the more I repeated a comment, the more experience I gained making my comments seem fresh and original. Scripting interactions like this gave me confidence and at times a feeling of control over my comments and views because I was able to keep the focus of the interview more on my research, the findings, and other sociological knowledge, and less on the other directions taken by reporters, hosts, and producers. I discovered that my entrances and exits in my performances might be as important as the content of the interviews. Creating a good first impression and leaving with a good last impression may be in the best interest of media relations because these impression management strategies may contribute to favorable coverage, further requests for interviews, or possible contact in the future. I tried to remember that although media relations are valuable, these interactional strategies should not be used at the expense of the sociological message.

In my effort to present a professional image, the impression management strategies I used and my attempt to avoid any "misrepresentation" (Goffman 1959: 58-66), "communication out of character" (Goffman 1959), or false impressions also included what I term image strategies. Image strategies, which were limited to television appearances, included the ways in which I evaluated my appearance or "personal front" (i.e., dressing in suitable and appropriate attire, and not appearing too casual, or sloppy, slovenly, or unkempt) (Goffman 1959: 23-24; Stone 1962). These strategies, which were not to be taken for granted, were influenced by the type of television program and the "setting" (Goffman 1959: 22) where the interview took place. In an effort to convey the "expert image," the television production crews (i.e., university, and regional and national broadcast/cable networks) prepared the setting in the "front region" (Goffman 1959: 107) before each prerecorded or live interview. Frontstage preparation involved the use of various methods to create a certain impression. For example, the crew manipulated the scenery and emphasized certain stage props (Goffman 1959: 22). This included rearranging office space (e.g., moving furniture, books, plants, and personal objects), adjusting the lighting, and providing advice and instruction about my body language (e.g., facial expressions). Similarly, the university production crew made sure that the set (e.g., backdrop, furniture, and lighting) was arranged appropriately before I participated in a prerecorded or live interview. 


\section{Managing Media Desocialization}

Like Adler (1984: 321-22) and Best (1986: 380), I experienced certain aspects of media desocialization as the attention to me and my research tapered off after each media experience. Although I knew the media attention had to end, I was not as prepared as I thought I would be when eventually it faded away. Initially, through a media socialization process and thus a self-transformation process involving the acquisition of media skills, the unexpected and constant media and public interest required an adjustment to a resocialized media self. After the attention and interest subsided after each media experience, another adjustment process emerged as I desocialized from my media self and the expert role and transitioned back into my scholar self and the professional role. For the most part, I appreciated the fact that the seemingly endless voice mail and e-mail messages disappeared. At times during media experiences, I was reluctant to turn on my computer or check my voice mail because I knew that messages were waiting for me. It had become a fairly common routine to sort them out, to play voice mail or e-mail tag in scheduling interviews or appearances, leave messages, return messages, prepare for interviews or appearances, and wonder about the quality of the interviews or appearances or how they would be received by the audiences - all of which made demands on my time, resources, and energy. Fortunately, my transition to less media and public interest was balanced with other responsibilities.

Although I did not define myself as a celebrity, my experiences were somewhat similar to Adler's (1984: 320-24) as I "came down to earth." Because of the emotional highs and lows, and the intensity, regularity, and duration of the effort involved in using emotion management strategies (and the extent to which I came to rely on these strategies), I found it difficult but necessary to emotionally decompress from my media involvement. For instance, I no longer had to get "up" when emotionally exhausted or ambivalent, or rely on surface acting or deep acting strategies to manage my anxiety, nervousness, or self-doubts. The depth of this decompression process surprised me. At times during this process, I was emotionally drained and experienced a sense of loss and emptiness (e.g., Adler 1984: 321), yet I was partially reluctant to give up my involvement. Although I did not actually enjoy it, I initially missed the excitement, elation, and "rush" of doing the interviews and related activities. However, after each media experience, I primarily welcomed my return to media obscurity, feeling much richer for each experience because I had been given an opportunity to share my research with the public.

\section{On-the-Job Training: The Emergent Realities of Media Work}

In my effort to communicate with the public through my engagement with the media, I confronted many new situations and made numerous difficult decisions, but I did not do it alone. My ability to define challenging situations and make important decisions as I encountered the emergent realities of media work involved relying on media-trained professionals as backstage support. With their help and guidance, I learned to use selected interviewing strategies and adapted to different media formats. 
When I look back on my relations with the media staff at my university and the ASA public information staff, I agree with Best (1986: 380) and others in recognizing "the importance of public relations in shaping news coverage." Media involvement has made me aware of the ways in which public information specialists interact with the media, and how they can facilitate broader awareness of sociological knowledge and research. In addition, it has led me to understand that working with the media requires a coordinated effort involving both public information specialists and sociologists. This concerted teamwork can be in the best interest of the discipline and the university, and it reflects a mutual concern with the communication and transmission of important information.

As worthy and wise stagehands, the public information staff provided invaluable support, feedback, information, and advice during my first media experience at the ASA conference. I would have been lost without their help, and it became the basis of my media socialization and thus my media training. I continue to rely on it. Together in the back region, we evaluated my performances between each interview and, when possible, right after I hung up the telephone. I asked and was thankful for their constructive criticism of my interviews and they kindly offered their views and support. They identified the communication and linguistic strategies and techniques that seemed to be most effective for both newspaper and radio interviews (i.e., avoiding sociological jargon, avoiding long pauses, avoiding flippant comments, using correct enunciation, raising and lowering my voice for emphasis, avoiding long sentences, being patient, being polite, having a sense of humor, avoiding "umms" and "ahhs," responding to questions fairly quickly, and not speaking too slowly or rapidly). They did a splendid job of bolstering my wavering confidence before and after the interviews, particularly the live radio interviews. As a "team" (Goffman 1959: 79), we collaborated backstage in ways that proved to be strategically instrumental in my performances. Similar backstage collaboration continued in my later media experiences when I received similar extensive support from the media staff at my university, especially when doing prerecorded and live television interviews. Although much of what I experienced was relatively new to me, it was not new to these specialists. Their support, including their able assistance with setting up and recording a mock interview for evaluation, enabled me to prepare more effectively for television interviews, and served to further sensitize me to the media culture.

Building on Goffman's (1981b) idea of the "radio talk" used by radio announcers, I have generally come to view this strategy as "media talk." Like radio announcers/hosts and television hosts, I was careful to put my "best foot forward" (Goffman 1981b: 198) when doing live radio and television interviews. When engaging in media talk, it became necessary to be aware of the issues frequently associated with speech production (e.g., speech lapse, stutter, gaffe, or slip of the tongue) (Goffman 1981b: 203), and to avoid "creature releases" like burps, hiccups, sneezes, and coughs (Goffman 1981b: 266). Although I was aware of these potential problems, the support and instruction I received from media staff regarding these and other issues was essential to developing an effective media face. 
Like other sociologists (e.g., Stacey 2004), I have not always been satisfied with my media involvement. When I began to question whether my involvement should continue, I was reassured that my department would always be supportive. I have since learned that this kind of collegial support may not be common. My colleagues also provided significant support, much of which was unsolicited (e.g., they encouraged me, offered advice, used humor and other strategies to help me cope with stress, supported my decisions, and did not emphasize or exaggerate the importance of media work). I was fortunate to be part of and benefit from these different forms of backstage collaboration.

\section{Using Selected Interview Strategies}

As a media-defined expert, I was expected not only to provide responses to producers', journalists', and reporters' questions, but to provide the "right" responses to their questions. I did not always do this and, in fact, provided responses that challenged them. Their expectations required my use of certain interview strategies to address misconceptions, distortions, or misinformation about the wives and/or the sport marriage. For example, like Best (1986: 377), a strategy I used consistently was to repeat one central point: "These wives are strong, intelligent, resilient, and adaptable." Beginning with my initial media experience, I realized that repeating my comments consistently in the interviews was important, and that varying my comments could create unnecessary confusion, impair my credibility, tarnish reputations, or worse.

Eventually, I learned that it is possible to have some measure of control during and after print interviews and during prerecorded and live television interviews. For instance, I frequently made it clear that I could not comment on a particular issue or story because my comment would be speculative or it did not relate to my research. On one particular occasion, before I consented to do a newspaper interview, the journalist and I agreed that I would have the opportunity to review a draft of the copy in order to clarify the information and provide additional information to ensure the article's accuracy before it was published. In this type of situation, an interviewee might request certain conditions, or a reporter might suggest such an arrangement to encourage the interviewee to participate. Nevertheless, after the article is drafted, the editor has final approval of the article's content, so this type of agreement still provides only limited control. It is also possible to have some control during a live television interview. I was reminded more than once by the media staff at my university that the host cannot make me say anything I do not want to say. Thus, when appearing live on a television program, when the interview strayed from my research topic, I learned that I could tactfully refuse to respond to a question, or I could say that commenting on that topic was beyond my expertise, or I could say that I did not know the answer to the question, or I could steer the interview back to my research topic. I relied on these strategies during live radio interviews, pleasantly and good-naturedly, when the hosts were hostile, antagonistic, condescending, or unusually critical. Some hosts may have a different or hidden agenda and want to discuss issues or topics that a guest does not wish to address, or they want to prove 
they know more than the guest, or they want to have "good" program for their audience at the expense of the guest. A slightly greater measure of control is possible during prerecorded radio and television interviews, since the recording can be stopped at any point (or edited for later broadcast) and time can be taken to reflect before responding, or a comment can be rephrased more than once, or the interviewer (i.e., producer) can be asked to clarify or repeat a question.

\section{Adapting to Different Media Formats}

During my media experiences, I discovered some major differences between the media formats of television, radio, newspaper, print magazine, and online magazine interviews. For example, I found television and radio interviews a bit unnerving because, unlike a class lecture or speaking engagement, they ended so quickly. Comments had to be swift and sure. Whether prerecorded or live, but particularly live, the fleeting nature of these media formats was stressful because they were short and emotionally intense. I was well aware that losing my composure or my train of thought when making a point, pausing while I tried to think of an effective word, comment, or a "catchy" phrase without appearing to be at a loss for words, or any other faux pas would be easily detected and magnified during live television and radio interviews. In contrast, mistakes in a prerecorded television and radio interview were less stressful because they would be edited for later broadcast. During live television and radio interviews, I often wished I could think more quickly and provide more concise, informative, wittier, or insightful comments. I felt this way because of the presence of live audiences, and because prerecorded and live television and radio interviews may be used as sound bites or in their entirety. Therefore, as a short-term interview situation, the immediacy of live television and radio interviews was stressful. Conversely, as a long-term interview situation, the repetitive questions posed to me during live television and radio interviews provided opportunities to rehearse my comments, to focus on the main points I wanted to emphasize, and to be a more effective interviewee in the future. Newspaper, print magazine, website, and online magazine interviews were initially less stressful and more relaxed because there was more flexibility and they offered more opportunities to develop and clarify my comments, ask questions, and provide examples. Then again, these types of interviews can be stressful because once the article is available to the public it can become permanent and may be used in any way for any purpose. This became abundantly clear to me when I discovered that articles and stories I had been interviewed for, or were written about my research, were posted on numerous diverse websites.

In addition to my attempts to adapt to various media formats, I discovered that balancing the demands of media involvement with other professional responsibilities was challenging, and during my later media experiences I became more sensitive to certain professional issues. Because of my academic responsibilities, time constraints, financial considerations, and escalating requests from television producers to appear on their programs, and because I did not wish to become overexposed, I prioritized my involvement by making specific distinctions between media formats. 
Eventually, I decided to distinguish between what I regarded as strictly news media and entertainment or "infotainment" media. Because I did not have an agent or a publicist to advise me, I discussed this issue with the media staff at my university, my family, colleagues, and friends. Deciding to limit my involvement to news media, and making finer distinctions in my selection, I declined requests for entertainment or infotainment television appearances. Also, in view of the fact that media interest did not recede but in fact continued to build and sustain itself, I wanted to make every effort to distinguish my research findings and knowledge of sport marriages from the details of a fast-breaking or developing news story. I did not want my research findings to be misinterpreted or lost in the coverage of a sensationalized story. For these reasons, I consistently avoided commenting on the story itself, and restricted my comments to my research findings. Whenever possible, I established the ground rules for my participation. In this way, I was able to assert some measure of control over how my image and my message were used by the media.

\section{Lessons for the Discipline: Professional Sociology and the Media}

My unanticipated experiences working with the media helped me to acquire a unique kind of professional training that I would not have otherwise acquired, and made me and my research useful to the public in ways I had not imagined. Nonetheless, I believe I would have greatly benefited from some formalized media training prior to my initial encounters. Given my lack of experience, I could only hope to minimize my mistakes. During these stressful experiences, I wondered how much more effective I could have been in the interview process and how much less anxiety I may have experienced had I been properly trained. Some sociologists suggest that media awareness or training is not as important as the acquisition and practice of basic professional skills (e.g., teaching, research, administration, conference participation, scholarly publications, and policy development), and thus should not be included or emphasized as part of our professional training. I suggest that sharing our sociological knowledge and research with the public - especially with those who would benefit most — has historically been the mission of the discipline. ${ }^{5}$ Delivering on this mission does not seem to be as effective for sociology as it has been for other social sciences that have established a disciplinary identity with the public. As I discovered, it is a monumental task to educate the media, and thus the public, about sociological knowledge and research. It can be difficult to be comfortably descriptive, informative, and concise in explaining sociological theories, concepts, processes, and research, particularly because the media are primarily interested in easily summarized facts (e.g., sound bites), or stories that sell news or entertainment. Engaging the media without sensationalizing controversial issues or research findings can be quite challenging, especially for a media novice.

\footnotetext{
${ }^{5}$ More recently, "public sociologies" was the theme of the 2004 ASA annual meeting and the focus of Burawoy's (2005a) presidential address.
} 
In contemporary society, universities - particularly land-grant universities - are expected to deliver education in ways that are relevant to the populations and communities that support them. To engage and inform the public, they are making attempts to disseminate research-based knowledge and provide educational services to enhance the quality of life and address social issues. To this end, they offer online courses, professional training for working adults, extension programs, and much more-all representing efforts to make scholarship more accessible and usable to wider audiences. To support these efforts and to augment unstable budgets due to decline in public funding, universities are increasingly recognizing the media as another meaningful way of delivering knowledge to and strengthening ties with the community. As a discipline, we should play an active part in this process-without sacrificing academic freedom and integrity - not only because it is the right thing to do, but because it may prove critical to our survival as a discipline. We should take media relations more seriously - it must not be left to chance.

On the basis of my significant firsthand experiences, I offer here some guidelines for working with the media. To ensure that sociology remains a viable and relevant discipline in what is and what will continue to be a media-driven society, I suggest that we must: (1) clarify the part media participation plays in sociology and our careers, (2) recognize the need for professional media training for current and future sociologists, (3) establish a code of ethics for media relations, and (4) actively promote media relations through the ASA and regional associations.

\section{Sociologists and the Media}

Sociologists can no longer be ivory tower thinkers. We have a responsibility to be more aware of the media and how it functions. The demands and pressures of the marketplace, government, and public opinion require the discipline to engage in activities that matter and to be able to address and discuss social issues, social phenomena, and public policies in accessible ways. We should think sociologically about the media and recognize how it functions. For instance, "urgency" and "immediacy" are social constructions driven by the competition and culture of the agencies and organizations that report the news or produce infotainment. The ability to think critically about the media will prevent us from falling prey to the media culture and its needs, and will help us to better understand and control our involvement. Sociologists must know why they are participating in, for example, a fast-breaking or developing news story or documentary, and what to avoid or emphasize. We must be aware that deciding not to engage may result in the media finding other individuals who are willing - perhaps those who are less qualified or unqualified, or those who may be unscrupulous, unethical, or lack credibility. As a result, facts or information could be distorted, or the public could be confused or misled.

Sociologists should discuss and clarify with their superiors (particularly department chairs) the part media participation plays in their careers (e.g., professional expectations regarding contribution to the reputation of the department and university, and public engagement as an extension of teaching and research), 
including whether and how these activities affect tenure, promotion, and salary increases. As Aminzade (2004) has observed, universities are beginning to reconsider reward structures to encourage scholars to engage the public. In this spirit, media engagement should be viewed as a form of public engagement. Sociologists should strategize with colleagues to enhance the department's presentation and public presence in the community. The media involvement of pioneering sociologists can help to create a disciplinary identity that the public will find reassuring, and perhaps rely on in times of crisis.

\section{Media Training for Sociologists}

The discipline prepares future sociologists to teach, initiate and conduct research, and publish. However, they are not prepared for, and they may lack adequate skills to engage in, some forms of public discourse. Media training may be viewed as a professional necessity for several reasons. For instance, a striking feature of the media culture is the surprise or "gotcha" element that is characteristic of fastbreaking news coverage. Sociologists may not give much thought to how others will respond to their work, making them vulnerable to being caught off-guard by unanticipated media attention. Some level of awareness and training prior to being approached by the media can help prepare for this media interest. Also, because of time constraints, duties and responsibilities, and resource limitations, it is important to distinguish between established media outlets and those that are less prominent or less reputable. This awareness, particularly when media representatives have deadlines, can result in making timely decisions about who to work with. With media training and institutional support, sociologists will be in a much better position to prepare their remarks, to have more control in interview situations, to develop professional relations with the media, and to shape the ways in which their research, opinions, or comments are reported.

Sociologists who have had no previous experience or training must make an effort to be knowledgeable about their responsibilities when dealing with the media. They should be aware of media resources, contacts, and staff at their university. As part of their professional training, sociologists with established teaching and research careers should consider participating in mock print and on-camera interviews and evaluating their readiness to actively participate with the media. My own experience has taught me that giving live television interviews seems more manageable - although not necessarily less stressful - after participating in and evaluating simulated television interviews. Mock interviews can provide opportunities to develop and practice effective responses to basic questions, and to rehearse and refine responses to difficult questions. Studying these recorded interviews and receiving constructive feedback can help the potential interviewee to become a more effective interviewee and build credibility. They help to build confidence and focus on self-presentation, and help the potential interviewee feel more comfortable, think and respond more quickly and cogently, and more effectively manage stress. Institutional support in the form of department/university-sponsored workshops could focus on different aspects of media relations organized around certain topics or themes (e.g., avoiding exploitation by the media; prioritizing media outlets; utilizing media participation to maximize the best possible coverage; or applying 
impression, emotion, and stress management strategies), thus sensitizing sociologists to the nature and expectations of the media culture.

Sociologists must develop an awareness of and confront various fears and concerns associated with media relations; otherwise, a typical response to requests for interviews may be to decline or avoid the media. It is fairly common to be self-conscious and worried about our ability to represent our department, college, university, or profession. Fear of the media often includes the fear of making a mistake or embarrassing oneself or others, and of being misquoted, misunderstood, misrepresented, exploited, or plagiarized. We may have fears about comments or participation being taken out of context. However, as I have mentioned, interviewees can always ask to see how a journalist plans to use their remarks, at least in print. For television interviews, it is reasonable to ask for questions ahead of time. Also, the more familiar the interviewee is with the format, including the presenter, the easier it is to avoid ambushes or "shout downs" if the interview will clearly be an effort to ridicule the research or the interviewee.

A common concern is that of being perceived by colleagues as self-promotionala fear that may not be unfounded, because a sociologist's involvement with the media may lead other colleagues in the department to be directly or indirectly critical of their colleague. A sociologist may believe that involvement with the media may give a colleague - who may be perceived by the media, government, policy makers, communities, organizations, or agencies as an authority or expert-greater power in the department or university, or that the colleague is using media participation to legitimize views or research. Furthermore, because of the demands, rigors, sacrifices, and expectations inherent in our professionalization, or because of professional pride, many sociologists are concerned about the potential for distortion of sociological knowledge and research through popularization. Because the media is so pervasive and enables rapid communication, there is a tendency on the part of the media to attempt to reduce sociology to simplistic or taken-for-granted ideas and views. Thus, collegial disapproval (within the department, university, or nationally) may emerge if a sociologist's colleagues believe that regular involvement with the media can negatively affect the public's perception of the discipline. Media training can help to mitigate these fears and concerns. It should include an awareness of other aspects of media participation, and impart knowledge of various techniques and strategies that are useful when working with the media - many of which have been identified and examined in this article.

The ASA should encourage graduate programs throughout the country to be more aware and to improve the practice of public sociologies-less as a professional issue and more as a practice in the discipline. As a way of developing media skills as they transition into future academic careers, advanced graduate students might be required to participate in a seminar or workshop to gain experience presenting their research findings to a skeptical public. Departmental graduate programs or university-level graduate divisions could offer seminars or workshops that include, among other things, doing mock interviews and increasing awareness of media culture and media relations (e.g., addressing topics and themes relevant to media participation, and developing interactive skills). This aspect of professional development-supported by the ASA - may help to better prepare future leading thinkers and make the discipline more accessible to the public. 


\section{Code of Ethics for Media Relations}

Ethical concerns should be addressed and a code of ethics should be drafted. As an ethical guideline for media relations, a code of ethics could draw from existing formal and informal codes of ethics in the profession and apply them to media participation. ${ }^{6}$ A code of ethics would provide an informative and effective ethical guideline for sociologists and professional sociology, particularly for the media novice.

\section{Promoting Media Relations in the Profession}

The ASA should introduce, develop, and draft a formal statement emphasizing the importance of media relations within the discipline. Professional associations should form media committees that actively, specifically, and seriously address the issue of media relations as a significant aspect of professional development and training (e.g., conference paper sessions, thematic sessions, plenary sessions, special sessions, colloquium sessions, didactic seminars, and workshops; code of ethics; graduate programs; and distribution of current and relevant information about media relations). Additionally, the ASA should continue to sponsor media workshops at its annual meetings, but also clearly identify topics that address the professional needs of sociologists working with the media now or in the future (e.g., deciding how and when to become involved with the media, learning how to work with the media when promoting published works, or responding to fastbreaking or developing news stories). Regional associations should follow the lead of the ASA or take the lead in promoting media relations within the profession.

\section{Conclusion}

I selected my research topic because of its sociological importance, and not because of its media or public appeal. As the media showed increasing interest in this topic, I could have avoided the reporters, journalists, and producers, giving excuses as to why I was not available (e.g., too busy with professional obligations), or declined all offers for interviews - but I did not. I could have become caught up in the unexpected, unusual, and constant attention; given in to feelings of self-importance; or defined myself as a celebrity_but I did not. Instead, over time, although my media experiences were not entirely comfortable and I frequently felt awkward, I came to view working with the media as an extension of reporting my findings and therefore integral to my professional responsibilities. In the process, I discovered first-hand that media involvement comes with distinctive risks and challenges.

Media work has the potential to interrupt other academic and professional commitments (e.g., teaching, research, department/university service, and publishing). After many years of reflecting on these concerns, I decided to become involved

\footnotetext{
${ }^{6}$ For example, a formal code of ethics might be created by adapting and modifying sections of the ASA's code of ethics (American Sociological Association 1999) to make them applicable to media relations. For a less formal code of ethics, see Marx (1997).
} 
with the media for several reasons: I believe it is consistent with my university's vision of community engagement; I think service to the public can contribute significantly to university relations; and I support the profession's mission to bring sociology to the public. I consider my involvement with the media to be an extension of doing research, analyzing and presenting the findings, and teaching sociology. Although it was not easy, I was able to extend my service beyond the university and the profession to include the public without compromising my other professional duties. I learned that it is possible to mitigate the risks and meet the challenges without compromising my professional integrity or threatening my academic obligations.

It is important to recognize that sociological research generally has direct relevance to peoples' lives - otherwise why would we do it? I believe this means we have a responsibility to various publics to keep them informed about our research findings. For example, I feel a sense of responsibility to the wives who participated in the long-term ethnographic project, the wives who did not participate but who may benefit from the findings, and other interested publics. In the process of dispensing sociological knowledge and research about unique work/family and marital issues, I have attempted to increase the discipline's and public's awareness of how the wives of professional athletes experience their marriages, thereby debunking stereotypical images of these private and usually silent women. Access to media outlets has provided opportunities to fulfill this responsibility without exploiting them or contributing to prevailing stereotypes. As my experiences illustrate, involvement with the media can include making an effort to be accessible to producers, journalists, and reporters working on feature stories or documentaries with long-term or flexible deadlines. Additionally, we can provide a public service during a fast-breaking or developing news story by sharing specialized knowledge as a story unfolds in order to bring a sociological perspective to the discussion.

As one attempt to address the concerns in this area, I now organize sessions at regional conferences to provide opportunities for colleagues to examine and address the personal and professional issues they confront in their media experiences. The overwhelmingly positive response I have received from panelists and audiences regarding these sessions, and the encouragement I have been given to organize and offer media workshops, has reaffirmed my belief that it would benefit the discipline to integrate media training into our professional development and training. This type of professional sociology can lead to a more effective public sociology. In a society where the public demands ready access to information through mass communication channels like the Internet, if we want to maintain any control at all over how our research findings are interpreted and reported or how sociological knowledge is disseminated, we can no longer successfully remain isolated from the public. Furthermore, given that we may be called on to engage with the media at some point in our careers, developing an awareness of media relations and taking advantage of media training to cope with such intense interactions would better prepare us for these experiences. The more prepared sociologists are, the more confidently and accurately we can expect to report our findings and educate the public about sociology, and the more effectively we can establish our disciplinary identity with the public without finding ourselves at the mercy of the media's needs and interests. 


\section{References}

Adler, P. (1984). The Sociologist as Celebrity: The Role of the Media in Field Research. Qualitative Sociology, 7, 310-326.

Adler, P. A., \& Adler, P. (2005). The Identity Career of the Graduate Student: Professional Socialization to Academic Sociology. American Sociologist, 36, 11-27.

Altheide, D. L. (1984). The Media Self. In J. A. Kotarba, \& A. Fontana (Eds.), The Existential Self in Society (pp. 177-195). Chicago: University of Chicago Press.

Altheide, D. L. (1985). Media Power. Beverly Hills, CA: Sage.

Altheide, D. L., \& Snow, R. P. (1991). Media Worlds in the Postjournalism Era. New York: Aldine.

American Sociological Association. (1999). Code of Ethics and Policies and Procedures of the ASA Committee on Professional Ethics. Washington, DC: American Sociological Association.

Aminzade, R. (2004). The Engaged Department: Public Sociology in the Twin Cities.” Footnotes, 32(8), 9 (November).

Bellas, M. L. (1999). Emotional Labor in Academia: The Case of Professors. The Annals of the American Academy of Political and Social Science, 561, 96-110.

Best, J. (1986). Famous for Fifteen Minutes: Notes on the Researcher as Newsmaker. Qualitative Sociology, 9, 372-382.

Best, J. (2004). Why Don't They Listen to Us? Fashion Notes on the Imperial Wardrobe. Social Problems, $51,154-160$.

Boyns, D., \& Fletcher, J. (2005). Reflections on Public Sociology: Public Relations, Disciplinary Identity, and the Strong Program in Professional Sociology. American Sociologist, 36, 5-26.

Brady, D. 2004. Why Public Sociology May Fail. Social Forces, 82, 1629-1638.

Burawoy, M. (2005a). For Public Sociology. American Sociological Review, 70, 4-28.

Burawoy, M. (2005b). Combat in the Dissertation Zone. American Sociologist, 36, 43-56.

Duster, T. (1987). Graduate Education at Berkeley. American Sociologist, 18, 83-86.

Etzioni, A. (2005). Bookmarks for Public Sociologists. British Journal of Sociology, 56, 373-378.

Ferrales, G., \& Fine, G. A. (2005). Sociology as a Vocation: Reputations and Group Cultures in Graduate School. American Sociologist, 36, 57-75.

Gans, H. J. (2002). More of Us Should Become Public Sociologists. Footnotes, 30(6), 10 (July/August).

Goffman, E. (1959). The Presentation of Self in Everyday Life. Garden City, NY: Anchor/Doubleday.

Goffman, E. (1961). Role Distance. In Encounters: Two Studies in the Sociology of Interaction (pp. 83152). Indianapolis, IN: Bobbs-Merrill.

Goffman, E. (1963). Stigma: Notes on the Management of Spoiled Identity. Englewood Cliffs, NJ: Prentice-Hall.

Goffman, E. (1967a). Embarrassment and Social Organization. In Interaction Ritual: Essays on Face-toFace Behavior (pp. 97-112). Chicago: Aldine.

Goffman, E. (1967b). On Face-Work: An Analysis of Ritual Elements in Social Interaction. In Interaction Ritual: Essays on Face-to-Face Behavior (pp. 5-45). Chicago: Aldine.

Goffman, E. (1967c). The Nature of Deference and Demeanor. In Interaction Ritual: Essays on Face-toFace Behavior (pp. 47-95). Chicago: Aldine.

Goffman, E. (1981a). Response Cries. In Forms of Talk (pp. 78-123). Philadelphia: University of Pennsylvania Press.

Goffman, E. (1981b). Radio Talk: A Study of the Ways of Our Errors. In Forms of Talk (pp. 197-330). Philadelphia: University of Pennsylvania Press.

Hochschild, A. R. (1979). Emotion Work, Feeling Rules, and Social Structure. American Journal of Sociology, 85, 551-575.

Hochschild, A. R. (1983). The Managed Heart: Commercialization of Human Feeling. Berkeley: University of California Press.

Hochschild, A. R. (1990). Ideology and Emotion Management: A Perspective and Path for Future Research. In T. D. Kemper (Ed.), Research Agendas in the Sociology of Emotions (pp. 117-142). New York: SUNY Press.

Lee, A. M. (1976). Sociology for Whom? American Sociological Review, 41, 925-936.

Leidner, R. (1999). Emotional Labor in Service Work. The Annals of the American Academy of Political and Social Science, 561, 81-95.

Levine, F. J. (2001). Public Information and ASA's Giving Sociology Away. Footnotes, 29(8), 2, (November).

Mac Rae, H. (1998). Managing Feelings: Caregiving as Emotion Work. Research on Aging, 20, 137-160. 
Martin, S. E. (1999). Police Force or Police Service: Gender and Emotional Labor. The Annals of the American Academy and Social Science, 561, 111-126.

Marx, G. T. (1997). Of Methods and Manners for Aspiring Sociologists: 37 Moral Imperatives. American Sociologist, 28, 102-125.

McLaughlin, N., Kowalchuk, L., \& Turcotte, K. (2005). Why Sociology Does Not Need to Be Saved: Analytic Reflections on Public Sociologies. American Sociologist, 36, 133-151.

Nichols, L. T. 2005. Editor's Introduction: 'Reflections on Graduate Training in Sociology'. American Sociologist, 36, 3-4.

Nielsen, F. 2004. The Vacant 'We': Remarks on Public Sociology. Social Forces, 82, 1619-1627.

Ortiz, S. M. (1994). When Happiness Ends and Coping Begins: The Private Pain of theProfessional Athlete's Wife. Ph.D. dissertation, University of California, Berkeley.

Ortiz, S. M. (1997). Traveling with the Ball Club: A Code of Conduct for Wives Only. Symbolic Interaction, 20, 225-249.

Ortiz, S. M. (2001a). When Sport Heroes Stumble: Stress and Coping Responses to Extramarital Relationships among Wives of Professional Athletes. Paper presented at the annual meeting of the American Sociological Association, Anaheim, CA, August 18-21.

Ortiz, S. M. (2001b). How Interviewing Became Therapy for Wives of Professional Athletes: Learning from a Serendipitous Experience. Qualitative Inquiry, 7, 192-220.

Ortiz, S. M. (2002a). From Freeway Flyer to International News Figure: Reflections on Unexpected Media Fame. Paper presented at the annual meeting of the Society for the Study of Symbolic Interaction, Chicago, IL, August 17-18.

Ortiz, S. M. (2002b). "Constructing Dependency in Coping with Stressful Occupational Events: At What Cost for Wives of Professional Athletes?” Sociology of Sport Online 5(2) http://physed.otago.ac.nz/ sosol/v5i2/v5i2 2.html.

Ortiz, S. M. (2004). Leaving the Private World of Wives of Professional Athletes: A Male Sociologist's Reflections. Journal of Contemporary Ethnography, 33, 466-487.

Ortiz, S. M. (2005). The Ethnographic Process of Gender Management: Doing the 'Right' Masculinity with Wives of Professional Athletes. Qualitative Inquiry, 11, 265-290.

Ortiz, S. M. (2006). Using Power: An Exploration of Control Work in the Sport Marriage. Sociological Perspectives, 49, 527-557.

Raney, A. A., \& Bryant, J. (Eds.). 2006. Handbook of Sports and Media. Mahwah, NJ: Lawrence Erlbaum.

Shulman, D., \& Silver, I. (2003). The Business of Becoming a Professional Sociologist: Unpacking the Informal Training of Graduate School. American Sociologist, 34, 56-72.

Stacey, J. (2004). Marital Suitors Court Social Science Spin-sters: The Unwittingly Conservative Effects of Public Sociology. Social Problems, 51, 131-145.

Stone, G. P. (1962). Appearance and the Self. In A. M. Rose (Ed.), Human Behavior and Social Processes: An Interactionist Approach (pp. 86-118). Boston: Houghton Mifflin.

Turner, J. H. (2005). 'Is Public Sociology Such a Good Idea?' American Sociologist, 36, $27-45$.

Vaughan, D. (2004). Public Sociologist by Accident. Social Problems, 51, 115-118.

Vaughan, D. (2005). On the Relevance of Ethnography for the Production of Public Sociology and Policy. British Journal of Sociology, 56, 411-416.

Steven M. Ortiz received his Ph.D. from the University of California at Berkeley. He is Associate Professor in the Department of Sociology at Oregon State University. His areas of specialization include symbolic interactionism, family, gender, and sport. His research has focused on sport marriages, particularly how women experience their marriages to professional athletes. His work has appeared in journals such as Journal of Contemporary Ethnography, Qualitative Inquiry, Sociological Perspectives, and Symbolic Interaction. 